\title{
La Nutrición como modulador epigenético y su papel en la prevención de enfermedades
}

\author{
Nutrition as an epigenetic modulator and its role in disease prevention \\ Erika Durán-Vasquez, Esther Ramírez-Moreno ${ }^{b}$, Quinatzin Y Zafra-Rojas ${ }^{c}$, Nelly del Socorro \\ Cruz-Cansino $^{d}$, Luis Delgado-Olivares ${ }^{e}$
}

\begin{abstract}
:
Malnutrition can be caused by the deficiency of nutrients in the diet or by the excess of some of them, this can produce a state of oxidative stress (EOx) that affects both proteins, lipids and nucleic acids, altering various cellular processes such as division, communication, transport of nutrients, metabolism, also damaging cell membranes, making them more fragile, increasing cell death. All this results in the development of various diseases, which because EOx can also induce epigenetic modifications, these diseases can be transmitted to the next generations, increasing the proportion of sick people in the population. Therefore, the objective of this article was to review the literature on the effect that oxidative stress has on epigenetic modifications, in order to determine its effect on the health-disease binomial, to determine the role of Nutriepigenomics in the treatment and prevention of diseases associated with oxidative stress and malnutrition. For which a search was carried out, on the platforms of PubMed, Cochrane and Google Academic, using as search criteria the words oxidative stress, epigenetic modifications and Nutriepigenomics. This search included both research and review articles, obtaining a total of 75 reviewed, which showed that malnutrition gives rise to various diseases, through oxidative damage, by means of epigenetic control through hypomethylation and hypermethylation. This suggests that good nutrition is key to preventing the development of inherited diseases, through epigenome modification.
\end{abstract}

\section{Keywords:}

Malnutrition, Oxidative stress, Epigenetics, Nutriepigenomics.

\section{Resumen:}

La malnutrición, puede originarse por la deficiencia de nutrientes en la dieta o por el exceso de alguno de ellos, esto puede producir un estado de estrés oxidativo (EOx) que afecta tanto a proteínas, lípidos y ácidos nucleicos, alterando diversos procesos celulares tales como la división, comunicación, transporte de nutrientes, metabolismo, dañando también a las membranas celulares volviéndolas más frágiles, aumentando la muerte celular. Todo esto da como resultado el desarrollo de diversas enfermedades, Las cuales debido a que el EOx también puede inducir modificaciones epigenéticas, estas enfermedades pueden ser trasmitidas a las siguientes generaciones, incrementando la proporción de personas enfermas en la población. Por lo que, el objetivo del presente artículo fue hacer una revisión en la literatura sobre el efecto que el estrés oxidativo tiene sobre las modificaciones epigenéticas, con la finalidad de determinar su efecto en el binomio salud-enfermedad, para determinar el papel de la nutriepigenómica en el tratamiento y prevención de enfermedades asociadas al estrés oxidativo y malnutrición. Para lo cual se realizó una búsqueda, en las plataformas de PubMed, Cochrane y Google Académico, utilizando como criterios de búsqueda estrés oxidativo, modificaciones epigenéticas y nutriepigenómica. En esta búsqueda se incluyeron tanto artículos de investigación como de revisión, obteniendo un total de 75 revisados, los cuales mostraron que la malnutrición da origen a diversas enfermedades, a través del daño oxidativo, mediante el control epigenético a través de la hipometilación y la hipermetilación. Lo cual sugiere que una buena nutrición es clave para prevenir el desarrollo de enfermedades hereditarias, a través de la modificación del epigenoma.

\footnotetext{
${ }^{a}$ Universidad Autónoma del Estado de Hidalgo, https://orcid.org/0000-0002-2944-1411, Email: eridur27@gmail.com

b Universidad Autónoma del Estado de Hidalgo, http://orcid.org/0000-0002-9928-8600, Email: esther_ramirez@uaeh.edu.mx

c Universidad Autónoma del Estado de Hidalgo, https://orcid.org/0000-0002-5295-9972, Email: quinatzin_zafra@uaeh.edu.mx

d Universidad Autónoma del Estado de Hidalgo, http://orcid.org/0000-0002-6771-3684, Email: ncruz@uaeh.edu.mx

Autor de Correspondencia, Universidad Autónoma del Estado de Hidalgo, https://orcid.org/0000-0002-3506-8393, Email:
} 
Palabras Clave:

Malnutrición, Estrés oxidativo, Epigenética, Nutriepigenómica.

\section{Introducción}

Una alimentación balanceada y con un óptimo contenido de nutrientes de buena calidad, es un factor importante para el mantenimiento de un estado saludable y una buena calidad de vida. Sin embargo, una alteración en la composición de la dieta, puede producir una condición nutricional conocida como malnutrición, la cual incluye: 1) a la desnutrición, donde la nula o escasa ingesta de nutrientes no logra cubrir las necesidades nutricionales necesarias para el organismo, dando como resultado una pérdida de peso y retraso en el crecimiento y 2) al sobrepeso u obesidad, que se caracterizan por un exceso en el consumo de algunos nutrientes, principalmente de carbohidratos ( $\mathrm{HCO}$ ) y lípidos, por lo que el excedente energético se almacena en el organismo en forma de grasa, resultando en un incremento de peso corporal $^{1}$. De acuerdo a la Organización Mundial de la Salud (OMS), en el mundo existen 462 millones de personas con desnutrición y 1,900 millones con sobrepeso $\mathrm{u}_{\text {obesidad }}{ }^{2}$, lo que significa que aproximadamente el 31 $\%$ de la población mundial, porcentaje que va en aumento, presenta problemas nutricionales. Si bien, la malnutrición puede darse en cualquier etapa de la vida, cuando ésta se produce durante un periodo temprano del desarrollo fetal, se incrementa la probabilidad de desarrollar permanente obesidad, cardiopatías o alguna enfermedad mental en la edad adulta debido a que en esta etapa se inicia el desarrollo del sistema nervioso central. Mientras que, si ocurre durante la etapa media o final del embarazo, la probabilidad de desarrollar alguna de estas patologías disminuye ${ }^{1,3}$.

La malnutrición, es un problema que afecta el estado de salud de los individuos y sus descendientes ${ }^{4,5}$, principalmente por el estrés oxidativo (EOx) que se produce durante la desnutrición u obesidad, el cual tiene un efecto epigenético (Tabla 1), término que se refiere a la modulación de la expresión genética mediante modificaciones de la estructura y organización del DNA, sin que esto signifique un cambio en la secuencia de sus bases, las cuales son heredables. Por lo que, el objetivo de la presente revisión fue determinar el papel que el estrés oxidativo tiene sobre las modificaciones epigenéticas, con la finalidad de determinar su efecto en el binomio salud-enfermedad, para determinar el papel de la nutriepigenómica en el tratamiento y prevención de enfermedades asociadas al estrés oxidativo y malnutrición. Por esta razón, realizamos una revisión en la literatura sobre el daño oxidativo y las modificaciones epigenéticas, así como el papel de la nutriepigenómica en la prevención y tratamiento de enfermedades asociadas a la malnutrición.

Para esta revisión, y con la finalidad de incluir la mayor parte de la información, se utilizaron las bases de datos de PubMed, Cochrane y Google. La búsqueda se realizó sobre información publicada de la fecha actual hacia diez años atrás. Sin embargo, cuando la información resultó relevante, artículos con fecha posterior fueron considerados.

\section{Malnutrición y estrés oxidativo}

El oxígeno es vital para la vida de los organismos aerobios, sin embargo su uso tiene un costo elevado para ellos, debido a que durante el metabolismo aerobio los peroxisomas, retículo endoplásmico, pero principalmente las mitocondrias producen especies reactivas de oxígeno (ERO), las cuales incluyen al oxígeno singlete $\left({ }^{1} \mathrm{O}_{2}\right)$, el radical anión superóxido $\left(\mathrm{O}_{2}^{--}\right)$, el peróxido de hidrógeno $\left(\mathrm{H}_{2} \mathrm{O}_{2}\right)$ y el radical hidroxilo $\left(\mathrm{HO}^{-}\right)$, siendo éste último altamente tóxico para las células ${ }^{22,23,24}$. En condiciones normales las ERO, cumplen funciones biológicas importantes, como la regulación de la insulina, la secreción de hormonas del crecimiento, actúan como segundos mensajeros en diversas rutas celulares, participan en la activación de factores de transcripción, así como en los procesos de defensa contra agentes infecciosos tales como bacterias y virus, esto último mediante su fagocitosis por los leucocitos en cuyo interior los bombardean con $\mathrm{ERO}^{25},{ }^{26}$. Sin embargo altas concentraciones de éstas especies oxidantes, son dañinas para la célula, por lo que sus niveles intracelulares son controlados por los antioxidantes, moléculas que se encargan de inactivar a las ERO, los cuales se dividen en dos grupos, los antioxidantes endógenos, que son producidos por el mismo organismo y los antioxidantes exógenos, que provienen de fuentes externas.

Durante la malnutrición existe una baja ingesta de frutas y verduras, disminuyendo así la ingesta de antioxidantes exógenos, mientras que se incrementa en el consumo de alimentos ricos en grasa y azúcares, por lo que se produce un aumento en la concentración intracelular de las ERO, lo cual sobrepasa la capacidad de los antioxidantes endógenos, provocando un desbalance entre la producción de las ERO y la capacidad de inactivarlos por parte de los antioxidantes, a lo que se le conoce como estrés oxidativo ${ }^{28}$, fenómeno que da lugar a la oxidación de lípidos, proteínas y ácidos nucleicos, afectando la estructura y función celular. 
Tabla 1. Enfermedades relacionadas con desnutrición y epigenética

\begin{tabular}{|c|c|c|c|}
\hline Enfermedad & Gen & Mecanismo epigenético & Referencias \\
\hline \multicolumn{4}{|l|}{ Desnutrición } \\
\hline Esquizofrenia & CD224 & $\begin{array}{l}\text { La hipermetilación de genes que promueven el } \\
\text { proceso inflamatorio, lo cual está relacionado con } \\
\text { los síntomas de alucinación. }\end{array}$ & 6 \\
\hline $\begin{array}{l}\text { Trastorno depresivo } \\
\text { mayor (depresión) }\end{array}$ & MORC1 & $\begin{array}{l}\text { Modifica la composición de lípidos provocando } \\
\text { una disminución en la densidad del hipocampo, } \\
\text { amígdalas y la corteza prefrontal, así como una } \\
\text { alteración en las funciones neuroquímicas. }\end{array}$ & 7 \\
\hline Insuficiencia cardiaca & PDK4 & $\begin{array}{l}\text { Existe un efecto en los cardiomiocitos que } \\
\text { generan la hipertrofia mecánica-transduccional. }\end{array}$ & 8,9 \\
\hline Alzheimer & ANK1 & Produce malformación en la corteza cerebral. & 10 \\
\hline \multicolumn{4}{|l|}{ Obesidad } \\
\hline \multirow[t]{2}{*}{ Diabetes tipo 2} & PPARGC1A & $\begin{array}{l}\text { Provoca reducción de secreción de insulina por } \\
\text { las células } \beta \text { del páncreas. }\end{array}$ & 11,12 \\
\hline & & Mayor porcentaje de $\mathrm{HbA}$. & \\
\hline Aterosclerosis & Dinucleótido CpG & $\begin{array}{l}\text { Aumenta la expresión de citosinas } \\
\text { proinflamatorias como IL8 y MCP1. }\end{array}$ & 13 \\
\hline Síndrome metabólico & PPARGC1A & $\begin{array}{l}\text { Altera la regulación del metabolismo oxidativo y la } \\
\text { liberación de insulina }\end{array}$ & $14,15,16$ \\
\hline Enfermedad Renal & RASAL1 & $\begin{array}{l}\text { Existe una actividad del fibroblasto, la metilación } \\
\text { de este gen causa la permanente activación de } \\
\text { fibroblastos. }\end{array}$ & 17 \\
\hline Cáncer de mama & ESR1 & $\begin{array}{l}\text { En el gen ER- } \alpha \text { se metila y se involucra con la } \\
\text { generación de tumores cancerígenos. }\end{array}$ & 18 \\
\hline Cáncer colorrectal & APC & $\begin{array}{l}\text { Desestabilización de fibras de cromatina. } \\
\text { Se encarga de la supresión de tumores que actúa } \\
\text { en la fase y favorecen la metástasis. } \\
\text { Daño al sistema de replicación de DNA. }\end{array}$ & 19,20 \\
\hline Cáncer cervicouterino & hTERT & $\begin{array}{l}\text { Este gen es promotor de lesiones precursoras } \\
\text { asociadas a la progresión del cáncer } \\
\text { cervicouterino. }\end{array}$ & 21 \\
\hline
\end{tabular}

La oxidación de los ácidos grasos resulta en la peroxidación lipídica, la cual daña a las membranas celulares, alterando su permeabilidad, estructura y función, debido a que se vuelven más frágiles. Mientras que, la oxidación de las proteínas puede ser reversible o irreversible, este daño se produce a través de la oxidación los aminoácidos lisina, prolina, arginina y treonina lo que da lugar a la formación de grupos carbonilo resultando en la pérdida de la estructura de la proteína. Las ERO también dañan al ácido desoxirribonucleico (DNA), induciendo la ruptura de la cadena sencilla $y$, aunque menos frecuente, la ruptura de la doble banda, dando lugar a mutaciones mediante la modificación de los nucleótidos o apareamiento entre las bases CG/AT. Las ERO también pueden interaccionar con la citosina de las islas CpG modificando los patrones de metilación del DNA. ${ }^{29,30}$.

Así, a través del daño oxidativo sobre las biomoléculas celulares, se pierde la funcionalidad de tejidos y órganos resultando en el desarrollo de diversas enfermedades metabólicas (diabetes, síndrome metabólico), neurodegenerativas (Alzheimer, Parkinson, esquizofrenia, demencia), enfermedades cardiovasculares, hipertensión, enfermedades dentales, diferentes tipos de cáncer, envejecimiento prematuro, enfermedad pulmonar obstructiva crónica, enfermedad renal crónica, lupus, entre otras. De tal modo que el estrés oxidativo afecta el estado de salud, calidad y el tiempo de vida de las personas y de sus descendientes a través de mecanismos epigenéticos ${ }^{31,32,33}$. 


\section{Modificaciones epigenéticas}

Las modificaciones epigenéticas, son reversibles actuando como como candados que abren o cierran la cromatina, mediante la relajación o condensación de la misma, para permitir o evitar que los factores de transcripción se unan a los genes ${ }^{34}$. Esto crea patrones de modulación y regulación de expresión epigenéticos en el individuo, los cuales pueden pasar a las siguientes generaciones 34,35 . Los mecanismos epigenéticos, mediante los cuales se lleva a cabo la regulación genética, son básicamente tres: la metilación del DNA, la modificación de histonas y los ácidos ribonucéicos no codificantes (ncRNA) ${ }^{11,35}$.

\section{Metilación del DNA}

La metilación se lleva a cabo por acción de las DNA metiltransferasas (DNMT), las cuales añaden grupos metilo en la posición 5' de la citosina del dinucleótido CpG, el cual se encuentra repetido en estructuras llamadas islas $\mathrm{CpG}$, en los genomas de los mamíferos, éstas llegan a tener una extensión de 300 a 3,000 pares de bases, las cuales se encuentran cercanas a las regiones promotoras, donde se lleva a cabo el inicio de la transcripción, lo que permite la regulación genética por esté mecanismo ${ }^{36,37}$. La adición de grupos metilo al DNA no permite la separación de ambas hebras, evitando la unión de la maquinaria de transcripción y la formación de nuevas moléculas de RNA. Existen dos mecanismos de regulación genética por metilación, 1) la hipermetilación donde se incrementa el número de grupos metilo unidos al DNA con lo cual la expresión de los genes es reprimida (silenciamiento genético), por lo que no hay una expresión de proteínas, y 2) la hipometilación, en donde se reducen los grupos metilo unidos al DNA permitiendo la expresión genética, lo que resulta en una sobreexpresión de proteínas. Por lo tanto, la modulación de la expresión genética depende de los procesos de metilación/desmetilación. Sin embargo, en ambos casos se puede producir un daño celular ya sea por la falta o por la acumulación de una proteína, la cual puede ser esencial en alguno de los procesos celulares ${ }^{11}$.

\section{Modificación de histonas}

La modificación de las histonas, incluye 5 procesos de adición o eliminación de grupos funcionales en los residuos aminoacídicos de estas proteínas, provocando que cambien su estructura o carga, afectando la estructura y estabilidad de la cromatina. Entre estas modificaciones se encuentran metilación, acetilación, fosforilación, ubiquitinación y ADP-ribosilación 38,39. La metilación de las histonas a diferencia de la que ocurre sobre el DNA, se lleva a cabo sobre ciertos residuos específicos de arginina y lisina presentes en las histonas a los cuales pueden unirse a uno o más grupos metilo. En la arginina se pueden obtener estructuras mono- y dimetil, mientras que en la lisina se forman mono-, di- y trimetil, es importante mencionar que la metilación de estos residuos a su vez puede inducir metilación de las hebras de DNA. Así, dependiendo de cuáles son los residuos metilados y del grado de metilación que exista en las histonas y en el DNA, se puede inducir la activación o represión genética. Por otro lado, la acetilación de las histonas involucra la transferencia de grupos acetil del Acetil-CoA a los residuos de lisina mediante la acción de las acetiltransferasas de histonas (HAT que comprende a cuatro familias GNAT, MYST y CBP/p300), con lo que se neutraliza la carga positiva de las histonas reduciendo la afinidad de las histonas por el DNA, el cual por los grupos fosfato presenta carga negativa lo que da lugar a una cromatina de estructura abierta activando la expresión genética. Mientras que la desacetilación, mediada por las desacetilasas de histonas (HDAC I, II, III y IV), produce un silenciamiento genético 38,40 . Por otra parte, la modificación por ubiquitinación, se lleva a cabo regularmente mediante la unión covalente de la ubiquitina a un residuo de lisina presente en las histonas (monoubiquinación), lo que da lugar al silenciamiento genético mediante la activación de la metilación. Tal es el caso la histona $\mathrm{H} 2 \mathrm{~B}$, que al estar monoubiquitinada induce la metilación de la histona $\mathrm{H} 3$ al igual que la unbiquitinación de la histona $\mathrm{H} 2 \mathrm{~A}$, induciendo la inactivación de uno de los cromosomas $\mathrm{X}$ en las mujeres, mediante el reclutamiento del complejo proteico polycomb 41. Mientras que, la adición de grupos fosfato a las histonas provoca un efecto estérico y un incremento de la carga negativa de las histonas, provocando que por el mismo tipo de carga del DNA ambas moléculas se repelan y, por lo tanto, algunos fragmentos de la cromatina se liberen permitiendo la expresión genética, efecto que se incrementa cuando se produce al mismo tiempo el proceso de acetilación ${ }^{42}$. Por último, la ADP-ribosilación que consiste en adicionar moléculas de ADP-ribosa a las proteínas, por medio de la transferencia de esta molécula por el $\mathrm{NAD}^{+}$. La ADP-ribosilación de proteínas interviene en diversos procesos celulares. En las histonas esta molécula se une preferentemente en las regiones $\mathrm{N}$ terminal básicas. Aunque puede haber histonas poli-ADPribosiladas (PAR), donde la ADP-ribosa puede ramificarse hasta 15 unidades de esta molécula unidas entre sí, la mayoría de las histonas son mono-ADP-ribosiladas (MAR). Si bien no está claro el papel de la ADPribosilación en la regulación epigenética, se ha reportado que la inhibición de la ADP-ribosilación induce a una hipermetilación ${ }^{43}$. 
Ácido ribonucleico no codificable (ncRNA)

Los ncRNA, son moléculas de RNA presentes en las células eucariotas que no codifican para ninguna proteína. Éstos se clasifican en pequeños (sncRNA, con menos de 200 nucleótidos) y largos (IncRNA, de 200 a más de 100 $k b)$. Los IncRNA, pueden actuar a nivel transcripcional al unirse a las histonas en regiones no metiladas remodelando la cromatina, como es el caso del IncRNAMBD1 el cual se une a la histona H19 formando un complejo que evita que la doble hélice del DNA se separe, por lo que no se puede iniciar la transcripción. Pero también puede actuar nivel post-transcripcional donde los IncRNA se pueden unir a proteínas reguladoras permitiendo la activación o represión de la transcripción ${ }^{44}$. Por otro lado, dentro del grupo de los sncRNA se encuentran los microRNA (miRNAs), los cuales, entre otras funciones, participan en los procesos de metilación del DNA y modificación de las histonas ${ }^{45}$.

Así, en conjunto las modificaciones epigenéticas actúan coordinadamente entre sí para lograr la modulación de la expresión de los genes, creando un patrón específico de marcas epigenéticas sobre el genoma (epigenoma), las cuales definen el perfil de expresión genética en cada célula y tejido. Estas modificaciones, se dan en respuesta a los estímulos ambientales que rodean al organismo ${ }^{46}$ como lo son el fumar, beber alcohol, exposición a contaminantes, hábitos laborales, alteraciones en los horarios de sueño, estado de ánimo, actividad física, estado redox, uso de diversos fármacos, infecciones por virus o bacterias, inflamación, edad, estrés oxidativo y componentes de la dieta, entre otros ${ }^{11}$. El epigenoma de un organismo define su estado de salud y enfermedad, debido a que este juega un papel importante en el desarrollo de diversas patologías como enfermedades dentales (enfermedad periodontal, caries), enfermedades cardiovasculares (hipertensión), trastornos mentales (esquizofrenia, depresión), diferentes tipos de cáncer, enfermedades metabólicas (diabetes, obesidad, resistencia a la insulina, síndrome metabólico), entre otras $11,47,48$.

\section{Nutriepigenomica}

Así, la modificación del epigenoma por efecto de los nutrientes presentes en los alimentos, da lugar a la nutriepigenomica, que es una ciencia nueva que está surgiendo como un campo emergente de investigación y que analiza las interacciones nutriente-epigenoma, con el propósito de utilizar los nutrientes como un mecanismo para la reprogramación del epigenoma, mediante intervenciones nutricionales o cambios de estilos de vida, y así modificar las marcas epigenéticas asociadas al desarrollo de enfermedades ${ }^{49}$.

La "hambruna holandesa de invierno", fue el primer antecedente de la importancia de la nutrición en la epigenética. Ocurrida durante el invierno de 1944, durante la segunda guerra mundial, donde la ocupación de los alemanes dejo sin alimentos a la población holandesa. Este hecho tuvo un gran impacto sobre las mujeres embarazadas, las cuales sufrieron diversos trastornos como pérdida de peso y problemas en la regulación de la presión sanguínea, lo cual afectó el desarrollo de los fetos. Después de la liberación por parte de las tropas de los aliados, todos los hijos de aquellas mujeres presentaron, en la etapa adulta, esquizofrenia. Investigaciones al respecto, mostraron que este hecho fue debido a las modificaciones epigenéticas sufridas durante la etapa fetal ${ }^{50}$.

Se ha demostrado que la etapa de vida, en la cual se produce la modificación del ambiente, es un factor importante en el desarrollo de las modificaciones epigenéticas. En cuanto a la desnutrición intrauterina, si esta se produce a partir de la mitad del primer trimestre, 0 al final del embarazo, resulta en una reducción del peso al nacer, mientras que si esta ocurre en la primera etapa del primer trimestre no hay una reducción de peso del neonato, pero si un aumento en la probabilidad de sufrir obesidad en la edad adulta, por lo que el menor peso al nacer no es un factor importante en la predisposición para el desarrollo de enfermedades en la adultez. Esto puede deberse a que, ante un ambiente intrauterino desfavorable, el feto realiza un ajuste de los procesos metabólicos para sobrevivir con la baja cantidad de nutrientes con los que dispone. Cuando después del nacimiento, el ambiente adverso cambia y existe una mayor disponibilidad de alimentos, se produce un desajuste en la maquinaria bioquímica del organismo, lo que da pie al desarrollo de enfermedades crónicas en la edad adulta. La desnutrición durante las primeras etapas del embarazo, afecta el desarrollo del sistema nervioso central dando lugar a problemas mentales, pero además a la alteración de la regulación del apetito, por lo que la ingesta excesiva de alimentos resulta en la obesidad. Otro factor importante son los intervalos de tiempo en los cuales se realizan los cambios de la dieta. Si estos son cortos, se producen modificaciones bioquímicas que aumentan la probabilidad de desarrollar enfermedades no transmisibles, sin embargo, esto no sucede cuando los tiempos de inanición intrauterina son mayores ${ }^{3}$.

Por otro lado, no solo el estado nutricio del organismo puede controlar el epigenoma, también los componentes de la dieta juegan un papel importante en la modulación de las modificaciones epigenéticas, las cuales son dosis dependiente y potencialmente reversibles. Estudios realizados en animales muestran que la administración de dietas con alto contenido de fructosa, produce hipermetilación de las regiones promotoras de los genes PPARa y CPT1A, lo que reduce su expresión afectando la $\beta$-oxidación de lípidos, lo que resulta en un incremento en 
los niveles séricos de triglicéridos, colesterol, resistencia a la insulina y síndrome metabólico ${ }^{51}$. Sin embargo, otro estudio reportó que el consumo de fructosa puede producir tanto hipometilación como hipermetilación de un gran número de locus en el hipotálamo y el hipocampo, lo que conduce a problemas de memoria, efectos pueden ser revertidos con la suplementación de ácido graso omega-3, ácido docosahexaenoico (DHA), logrando una mejora de capacidad cognitiva y la reducción los niveles séricos de triglicéridos, colesterol e insulina ${ }^{52}$, esto debido a que el DHA tiene la capacidad de restaurar los niveles basales de metilación y acetilación de las histonas tipo H3 ${ }^{52}$, por lo que el DHA y otros PUFA-n3 (ácidos grasos poliinsaturados omega 3) pueden prevenir trastornos mentales como Alzheimer, además de otras enfermedades como cáncer de colon, esto a través de modificaciones epigenéticas como hipometilación que permite la unión a factores de transcripción ${ }^{49,54}$.

También se ha reportado que el DAH y el EPA (ácido eicosapentaenoico) modulan la expresión de los miRNAs miR-146a, miR-146b, miR-21, miR-125a, y miR-155 los cuales están involucrados en los procesos de inflamación 55 .

Por otro lado, estudios in vitro muestran que los ácidos grasos saturados pueden inducir el desarrollo de cáncer, incrementando la expresión del miR-29a, mediante la inhibición post-transcripcional del RNA mensajero (mRNA) del sustrato receptor de insulina 1 (IRS-1), dando lugar a la resistencia a la insulina y diabetes, mientras que la expresión del miR-27b puede llevar a la inducción de arritmia ${ }^{55}$.

También se ha reportado que la deficiencia en vitamina $\mathrm{B} 12$, induce la hipometilación de las regiones promotoras de los genes SEEBF1 y LDLR, los cuales están involucrados en la regulación de la biosíntesis de colesterol. La sobre expresión de estos genes resulta en un aumento en la biosíntesis de colesterol en el tejido adiposo ${ }^{56}$.

Mientras que la deficiencia en el ácido fólico o vitamina B9, se encuentra asociada a la anemia, obesidad $y$ al desarrollo de modificaciones epigenéticas ${ }^{57,58}$ debido a que la baja o nula ingesta de esta vitamina produce hipometilación de elementos nucleares de intercalado largo 1 (LINE-1), el cual es un biomarcador de metástasis, incrementando el riesgo de desarrollar cáncer ${ }^{59}$ y enfermedades mentales como esquizofrenia y desorden bipolar ${ }^{60}$. Por lo que la suplementación con ácido fólico durante el embarazo puede revertir cambios epigenéticos importantes ${ }^{61}$. Un estudio realizado en ratas, muestra que la deficiencia en folato producida desde el destete hasta la pubertad, incrementa la metilación del DNA de las células del hígado ${ }^{62}$, lo que significa que el efecto epigenético de los nutrientes depende también de la etapa de vida en la que se encuentre el organismo.
Por otro lado, durante la oxidación de lípidos, por EOx, se produce la generación de 4-hidroxi-2-nonenal (4$\mathrm{HNE}$ ) y 4-oxo-2-nonenal (4-ONE), lo que permite la formación de aductos de DNA-proteínas, lo que afecta epigeneticamente la estructura y función de las histonas $\mathrm{H} 3, \mathrm{H} 2 \mathrm{~B}, \mathrm{H} 2 \mathrm{~A}$ y H $4{ }^{63}$, efecto que se encuentra implicado en el proceso de envejecimiento ${ }^{64}$.

También se ha reportado que el EOx produce lesiones oxidativas sobre el DNA de los espermatozoides, activando la desmetilación del DNA del genoma paterno y alterando los patrones de reprogramación epigenética en el desarrollo embrionario temprano ${ }^{65}$.

\section{Estrés oxidativo, Epigenética y Terapia antioxidante}

El EOx, puede modificar el epigenoma debido al efecto que las ERO tienen sobre la metilación, lo que permite que en un mismo sistema se produzca en el mismo tiempo tanto la hipo como la hipermetilación. Wongpaiboonwattana ${ }^{66}$, reportó que en células cancerosas de vejiga el EOx produce hipometilación en LINE-1, e hipermetilación en el promotor RUNX3, cuya proteína actúa como represor de tumoración. De acuerdo a los autores, esta dualidad de metilación puede darse por diversos factores, mientras que la hipometilación puede deberse a tres procesos, primero la eliminación de las $E R O$, donde se requiere de la síntesis del antioxidante endógeno glutatión (GHS), para lo cual es necesaria homocisteína que a su vez, para ser sintetizada requiere de S-adenosilmetionina (SAM) lo que provoca una depleción de ésta y puesto que SAM es el donador de grupos metilo, la DNMT no puede llevar acabo la metilación del DNA. Segundo, el ambiente oxidativo activa a la enzima de translocación ${ }^{10,11}$, que interviene en los procesos de desmetilación del DNA a través de hidrolizar a la 5-metilcitosina en 5-hidroximetilcitosina, la cual mediante el sistema reparación de la escisión bases es sustituida por una citosina desmetilada, y tercero, el EOx daña a las bases de guanina, formado 8-hidroxilguanina o 8-oxoguanina, modificando también a las guaninas del dinucleótido CpG, por lo que la metilación no se lleva acabo. Con respecto a la hipermetilación, esta puede darse por el ambiente oxidativo, lo que promueve la formación de complejos de silenciamiento genético DNMT-polycomb además de procesos de desacetilación.

Por otra parte, recientemente se ha reportado que durante la infección del virus SAR-coV-2, el cual produce la enfermedad del coronavirus 19 (COVID-19, por sus siglas en ingles), se incrementa la producción de las ERO produciendo un estado de EOx, como una respuesta para combatir al virus, sin embargo este estado de oxidación también induce la desmetilación del gen $A C E 2$, el cual codifica para la proteína ACE2 la cual funge como receptor del virus, por lo que la desmetilación del gen produce una 
Tabla 2. Alimentos con efecto epigenético y antioxidante utilizados en el tratamiento o prevención de enfermedades.

\begin{tabular}{|c|c|c|c|c|c|}
\hline Alimento & $\begin{array}{l}\text { Nutriente } \\
\text { compuesto }\end{array}$ & Efecto epigenético & Actividad antioxidante & $\begin{array}{l}\text { Enfermedad } \\
\text { asociada }\end{array}$ & Referencia \\
\hline Nueces & ácido anacárdico & $\begin{array}{l}\text { Inhibición en la acción de } \\
\text { acetiltransferasa }\end{array}$ & $\begin{array}{l}\text { Inhibición de producción de } \\
\text { óxido nítrico (NO) }\end{array}$ & Obesidad & 67 \\
\hline $\begin{array}{l}\text { Kokum } \\
\text { (Garcinia indica) }\end{array}$ & Garcinol & $\begin{array}{l}\text { Inhibe la histona } \\
\text { acetiltransferasa y ayuda a } \\
\text { prevenir el cáncer de } \\
\text { estómago al neutralizar los } \\
\text { radicales libres. }\end{array}$ & $\begin{array}{l}\text { Eliminación de radicales } \\
\text { anión superóxido, hidroxilo } \\
\text { y metilo }\end{array}$ & $\begin{array}{l}\text { Cáncer } \\
\text { (leucemia, colon) }\end{array}$ & 68 \\
\hline $\begin{array}{l}\text { Té verde y negro } \\
\text { A }\end{array}$ & Teofilina & Desacetilación de histonas & $\begin{array}{l}\text { Reducción en la actividad } \\
\text { de la ornitina } \\
\text { descarboxilasa, } \\
\text { responsable de la } \\
\text { catalización del proceso } \\
\text { regulatorio de la biosíntesis } \\
\text { de las poliaminas, } \\
\text { relacionado con la } \\
\text { carcinogénesis }\end{array}$ & Cáncer & 67,69 \\
\hline $\begin{array}{l}\text { Vino tinto, frutos } \\
\text { secos }\end{array}$ & Resveratrol & $\begin{array}{l}\text { Acetilación de histonas, } \\
\text { alteración de DNA } \\
\text { metiltransferasas y los RNA } \\
\text { de interferencia (iRNA) }\end{array}$ & $\begin{array}{l}\text { Inhibición de las actividades } \\
\text { ribonucleótido reductasa, y } \\
\text { de la proliferación celular y } \\
\text { de la carcinogénesis } \\
\text { inducida }\end{array}$ & $\begin{array}{l}\text { Aterosclerosis, } \\
\text { cáncer }\end{array}$ & $67,70,72$ \\
\hline Brócoli & indol-3-carbinol & $\begin{array}{l}\text { Acción inhibidora de WWP1 } \\
\text { reactiva la función normal } \\
\text { de PTEN como supresor de } \\
\text { tumores }\end{array}$ & $\begin{array}{l}\text { Activa el receptor de } \\
\text { hidrocarburo de arilo, que } \\
\text { se comunica con las células } \\
\text { inmunológicas y epiteliales } \\
\text { en el revestimiento } \\
\text { intestinal y previene la } \\
\text { inflamación causada por } \\
\text { bacterias nocivas }\end{array}$ & $\begin{array}{l}\text { Cáncer de } \\
\text { próstata }\end{array}$ & $71,72,73$ \\
\hline Calabaza & Selenio & $\begin{array}{l}\text { Disminuye el grado de } \\
\text { metilación en el DNA en } \\
\text { células epiteliales del colon }\end{array}$ & $\begin{array}{l}\text { Se encarga de destruir el } \\
\mathrm{H}_{2} \mathrm{O}_{2} \text {, que se forma como } \\
\text { consecuencia de la } \\
\text { oxidación }\end{array}$ & Cáncer de colon & 71,72 \\
\hline $\begin{array}{l}\text { Cereales, } \\
\text { hortalizas y } \\
\text { leguminosas }\end{array}$ & Folato (vitamina B9) & $\begin{array}{l}\text { Hipermetilación en } \\
\text { secuencia reguladora } 5 \text { del } \\
\text { gen h-cadherina }\end{array}$ & $\begin{array}{l}\text { Es un marcador para la } \\
\text { detección de EOx }\end{array}$ & $\begin{array}{l}\text { Cáncer (gástrico, } \\
\text { colon, mama, } \\
\text { tiroideo y } \\
\text { ovárico) }\end{array}$ & 74 \\
\hline $\begin{array}{l}\text { Productos de } \\
\text { origen animal y } \\
\text { hongos }\end{array}$ & Vitamina $\mathrm{D}$ y calcio & Metilación de DNA & $\begin{array}{l}\text { El calcio forma parte del } \\
\text { sistema antioxidante que es } \\
\text { sintetizado por la vitamina } \\
\mathrm{D} \text {, ya que cuando se } \\
\text { produce oxidación puede } \\
\text { afectar las terminales } \\
\text { nerviosas, que } \\
\text { desencadenan depresión }\end{array}$ & $\begin{array}{l}\text { Trastorno } \\
\text { depresivo mayor } \\
\text { (depresión) }\end{array}$ & 75 \\
\hline $\begin{array}{l}\text { Cítricos, } \\
\text { oleaginosas }\end{array}$ & Vitamina $\mathrm{C}$ y $\mathrm{E}$ & $\begin{array}{l}\text { Metilación de DNA y } \\
\text { miRNA }\end{array}$ & $\begin{array}{l}\text { Pertenecen al sistema de } \\
\text { defensa antioxidante, } \\
\text { atacando } \mathrm{a} \mathrm{O}_{2}{ }^{-}, \mathrm{OH}^{--} \text {y } \mathrm{NO}\end{array}$ & Esquizofrenia & 75 \\
\hline $\begin{array}{l}\text { Lácteos, frutas y } \\
\text { vegetales de color } \\
\text { naranja y amarillo }\end{array}$ & Vitamina A & $\begin{array}{l}\text { Modificación de histonas y } \\
\text { metilación de DNA }\end{array}$ & $\begin{array}{l}\text { Disminuye la oxidación de } \\
\text { la proteína } \beta \text {-amiloide en el } \\
\text { Cerebro }\end{array}$ & Alzheimer & 76 \\
\hline
\end{tabular}

sobre expresión de la proteína ACE2 la cual se une a la membrana celular facilitando la diseminación del virus en el organismo ${ }^{30}$. Es importante recordar que durante la desnutrición, sobrepeso y obesidad existe un estado crónico de EOx, por lo que se incrementa el riesgo de infección por SARS-Cov-2 y desarrollar la COVID-19. Por otro lado, se ha reportado que el uso de antioxidantes como el tocoferol acetato, que es un antioxidante sintético, fue capaz de revertir los daños causados por el EOx sobre los perfiles de metilación, tanto la hipometilación como en la hipermetilación, por lo que se ha propuesto que la terapia antioxidante podría prevenir las modificaciones epigenéticas ${ }^{66}$. A este respecto, existen diversos alimentos ricos en antioxidantes los cuales se ha reportado que tienen un efecto epigenético (Tabla 2), los 
cuales podrían ser utilizados en el tratamiento de diversas enfermedades epigenéticas.

La malnutrición, es un problema que actualmente, sufre gran parte de la población a escala mundial ${ }^{2}$. En sus dos extremos desnutrición y obesidad se produce un estado de EOx y por lo tanto, modificaciones epigenéticas estas últimas como una respuesta a los cambios del medio que rodea al organismo ${ }^{11,46}$. Es de notar la importancia de la nutrición intrauterina, debido a que en esta etapa se producen las modificaciones epigenéticas que se mantendrán a lo largo de la vida del organismo, por lo que la desnutrición intrauterina provoca cambios epigenéticos necesarios para que el organismo sobreviva con los pocos nutrientes con los que dispone, por lo que cuando las condiciones de su medio cambian, existiendo mayor acceso a los alimentos, se produce la obesidad ${ }^{3}$, la cual actualmente es considerada como una enfermedad pandémica que incrementa rápidamente, debido al ambiente obesogénico que nos rodea ${ }^{77}$. En la presente revisión, hemos mostrado evidencia del papel que juegan los componentes de los alimentos en las modificaciones epigenéticas, las cuales no solo afectan al individuo sino también a sus descendientes.

Es importante mencionar, que debido al actual confinamiento por el COVID-19, existe una alta probabilidad de que estén ocurriendo cambios en el epigenoma de gran parte de la población a escala mundial, debido principalmente a la modificación de estados de ánimo, mayor estrés y en gran manera el cambio de hábitos alimenticios y sedentarismo, el tipo de modificaciones que están ocurriendo, podrían incrementar el desarrollo de diversas enfermedades crónico no trasmisibles (como obesidad, diabetes e hipertensión), consideradas un factor de riesgo ante el contagio por el COVID-19, por lo que el número de casos positivos podría incrementarse al término del confinamiento, haciendo también susceptibles a las futuras generaciones.

\section{Conclusiones}

Los malos hábitos alimenticios de la población, ha traído como resultado un problema de malnutrición el cual ha producido modificaciones epigenómicas que se han transmitido a través de varias generaciones. Estas han dado lugar al desarrollo de diversas enfermedades no transmisibles, como las enfermedades cardiovasculares, cáncer, diabetes, entre otras. El estrés oxidativo juega un papel importante en las modificaciones epigenéticas por lo que la ingesta adecuada de antioxidantes naturales, contenidos en los alimentos, podría prevenir el daño oxidativo, cambiando el patrón de modulación del epigenoma, con lo cual se podría mejorar el estado de salud de la población y de las futuras generaciones. Por esta razón, el surgimiento de la nutriepigenómica, como ciencia emergente, podría ayudar a modificar los patrones de metilación, con la finalidad de prevenir e incluso revertir las modificaciones epigenéticas en pro de una vida saludable.

\section{Referencias}

[[1] Hurtado-Quintero C, Mejía C, Mejía F, Arango C, Chavarriaga LM, Grisales et. al. Malnutrición por exceso y déficit en niños, niñas y adolescentes, Antioquia, 2015. Rev Fac Nac Salud Pública. 2017; 35(1):58-70

[2] Organización mundial de la salud. ¿Qué es la malnutrición? 2016. https://www.who.int/features/qa/malnutrition/es/

[3] Schulz LC. The Dutch Hunger Winter and the developmental origins of health and disease. PNAS. 2010; 107(39):16757-16758.

[4] Aguila, Q, Ramón MA, Matesanz S, Vilatimo R, Del Moral I, Brotons C, et al. Assessment study of the nutritional status, eating habits and physical activity of the schooled population of Centiles, Hostalets de Balenyà and Sant Martí du Centelles ALIN 2014 Study. Endocrinol Diabetes Nutr. 2014; 64(3):138-145.

[5] Cederholm T, Barazzoni R, Austin P, Ballmer P, Biolo G, Bischoff SC. et al. ESPEN guidelines on definitions and terminology of clinical nutrition. Clin Nutr. 2017; 36(1):49-64.

[6] Akbarian S. Epigenetic Mechanisms in Schizophrenia. Dialogues. Clin Nuerosci. 2014;16(3):405-417.

[7] Tapia-Saavedra A. Estrés oxidativo y depresión ¿Un posible rol etiológico? Rev Chil Neuro-Psiquiat. 2005; 43(4):329-336.

[8] Hernández A, Duque J, Rosales W, Lizcano F. Perspectivas moleculares en cardiopatía hipertrófica: abordaje epigenético desde la modificación de la cromatina. Rev Col Cardiol. 2017; 24(2):146-152.

[9] Azevedo PS, Duarte DR, Minucucci MF, Matsubara BB., Matsubara LS, Novo R, et al. Rol de la lipoperoxidación en la intensificación de la remodelación ocasionada por el betacaroteno tras infarto. Arq Bras Cardiol. 2009; 93(1):32-36.

[10] Lunnon K, Smith R, Hanon E, De Jager., Srivastava G, Volta M. et al. Methylomic profiling implicates cortical deregulation of ANK1 in Alzheimer's disease. Nat Neurosci. 2014; 17(9):1164-1170.

[11] Nava-Rivera LE, Vázquez-Maya LE, Medina-García A, MacíasCastillo F, Suarez-Romero JF, Sharara-Núñez AI, et al. La Epigenética y su relación con enfermedades Crónico Degenerativas. Rev Med Torreón. 2016; 8(2):52-60.

[12] Fermin I, Milagro Y, Martinez JA. Epigenética en obesidad y diabetes tipo 2: papel de la nutrición, limitaciones y futuras aplicaciones. Rev Chil Endocrinol Diabetes. 2013; 6(3):108-114.

[13] Guardiola M, Vallvé JC, Zaina S, Ribalta J. Epigenética en la ateriosclerosis. Clin Investig Arterioscler. 2016; 28(2):102-119.

[14] Rubio-Guerra RF, Durán-Salgado MB. Disfunción del tejido adiposo y síndrome metabólico. Sx metabolic Diab. 2014; 1:

[15] Barrera L, Cassidy A, Jhonson IT, Bao Y, Belshaw N. Epigenetic and antioxidant effects of dietary isothiocyanates and selenium: potential implications for cancer chemoprevention. Procc Nut Society. 2012: 71(2):237-245. 
[16] Wang J, Zhenlong W, Defa L, Ning L, Scott V. Nutrition, Epigenetics, and Metabolic Syndrome. Antioxid Redox Sign. 2012; 17(2): 282-301.

[17] De la Torre M. Introducción a la epigenética, nuevo paradigma en nefrología. Sección de Nefrología. Hospital Universitario de Cabueñes. 2017; 9(1):1-103.

[19] Bhattacharyya A, Chattopadhyay R, Mitra S, Crowe SE. Oxidative Stress: An Essential Factor in the Pathogenesis of Gastrointestinal Mucosal Diseases. Physiol Rev. 2014. 94(2):329-354.

[18] Rodríguez-Ballesteros DC, García-Moreno-Mutio SL, Jaimes-Santoyo J, Barbosa-Cobos RE, De Montesinos A \& Beltrán-Ramírez O Metilación de ADN en cáncer de mama. Rev. Hosp Juarez Mex. 2015 82(3 y 4):165-168[19] Bhattacharyya A, Chattopadhyay R, Mitra S, Crowe SE. Oxidative Stress: An Essential Factor in the Pathogenesis of Gastrointestinal Mucosal Diseases. Physiol Rev. 2014. 94(2):329354 .

[20] Afanador CH, Muñetón CM. Epigenética del cáncer colorrectal. Rev Col Gastro. 2018. 33(1):32-40.

[21] Ríos-Romero M, Soto-Valladares AG, Piña-Sánchez. Alteraciones epigenéticas en la progresión de cáncer cervicouterino. Rev Med Inst Mex Seguro Soc. 2015; 53(2):S212-S217.

[22] Lobo V, Patil A, Phatak A, Chandra N. Free radicals, antioxidants and functional foods: Impact on human health. Pharmacogn J. 2010; $4(8): 118-126$

[23] Sharma P, Bhushan A, Shanker Dubey R, Pessarakli M. Reactive Oxygen Species, Oxidative Damage, and Antioxidative Defense Mechanism in Plants under Stressful Conditions. J botany. 2012; 2012, Article ID217037.

[24] Kausar S, Wang F, Cui H. The Role of Mitochondria in Reactive Oxygen Species Generation and Its Implications for Neurodegenerative Diseases. Cells. 2018; 7(274).

[25] Burton, G. J., \& Jauniaux, E. Oxidative stress. Best practice \& research. Clin Obstet \& Gynecol. 2011. 25(3):287-299.

[26] Kalia R., Sareen S., Nagpal A., Katnoria J., Bhardwaj R. (2017) ROSInduced Transcription Factors During Oxidative Stress in Plants: A Tabulated Review. In: Khan M., Khan N. (eds) Reactive Oxygen Species and Antioxidant Systems in Plants: Role and Regulation under Abiotic Stress. Springer, Singapore.

[27] Macedo-Márquez A. La producción de especies reactivas de oxígeno (EROs) en las mitocondrias de Saccharomyces cerevisiae. Rev Esp Cienc Quím Biol. 2012; 15(2):97-103.

[28] Viada E, Gómez L, Campaña IR. Estrés oxidativo. Correo CC Méd. 2017; 21(1): 171-186.

[29] de Araújo R, Bruneska D, Borba MA. Oxidative Stress and disease. Chapter 10. En: Morales-Gonzalez, J.A., Morales-Gonzalez, A., Madrigal-Santillan, E.O. editors, A Master Regulator of Oxidative stress - the Transcription Factor Nrf2. InTech. 2016: 185-199.

[30] Shawalha AH, Zhao M, Coit P, Lu Q. Epigenetic dysregulation of ACE2 and interferon-regulated genes might suggest increased COVID-19 susceptibility and severity in lupus patients. Clin Immunol. 2020; 2015:_1-4.
[31] Delgado Olivares L; Betanzos G; Sumaya-Martínez MT. Importancia de los antioxidantes dietarios en la disminución del estrés oxidativo Inv y CC, 50. 2010: 10-15.

[32] Kesarwala AH, Krishna MC, Mitchel JB. Oxidative Stress in Oral Diseases. Oral Dis. 2016; 22(1): 10-20.

[33] Liguori I, Russo G, Curcio F, Bulli G, Aran L, Della-Morte D, et al. Oxidative stress, aging, and diseases. Clinical interventions in aging.2018; 13: 757-772.

[34] Tiffon C. The Impact of Nutrition and Environmental Epigenetics on Human Health and Disease. Intl j of mol sciences.2018; 19(11), 3425 $1-19$.

[35] García RR, Ayala RPA, Perdomo Velásquez SP. Epigenética: definición, bases moleculares e implicaciones en la salud y en la evolución humana. Rev CC Salud.2012; 10 (1): 59-71.

[36] Janitz K, Janitz M. Assessing Epigenetic Information. In T. Tollefsbol (Ed.) Handbook of epigenetics. 2011: 173-181.

[37] Arroyo-Jousse V, García- Díaz DF, Pérez-Bravo F. La metilación global del ADN y los niveles de homocisteína en plasma se encuentran disminuidos en pacientes con diabetes mellitus tipo 1 . Rev Med Chile 2015;(143): 262-268.

[38] Krause BJ, Castro-Rodríguez AJ, Uauy R, Casanello P. Conceptos generales de epigenética: proyecciones en pediatría. Rev Chil Prediatr. 2016; 87(1): 4-10.

[39] Alhamwe BA, Khalaila R, Wolf J, Von Bülow V, Harb H, Alhamdan F, et al. Histone modifcations and their role in epigen Allergy Asthma. Clin Immunol. 2018; 14(39):_1-16.

[40] Miller JL, Grant PA. The Role of DNA Methylation and Histone Modifications in Transcriptional Regulation in Humans. Subcell Biochem. 2013; 61: 289-317.

[41] Shilatifar A. Chromatin Modifications by Methylation and Ubiquitination: Implications in the Regulation of Gene Expression. Annu Rev Biochem. 2006; 75: 243-269.

[42] Brehove M, Wang T, North J, Luo Y, Dreher SJ, Shimko JC, et al. Histone Core Phosphorylation Regulates DNA Accessibility. J Biol Chem. 2015; 290(37): 22612-22621.

[43] Hottiguer MO. Nuclear ADP-Ribosylation and Its Role in Chromatin Plasticity, Cell Differentiation, and Epigenetics. Annu Rev Biochem. 2015; 84: 227-263.

[44] Cao J. (2014). The functional role of long non-coding RNAs and epigenetics. Biological procedures online, 16, 11: 1-13.

[45] Zhou T. Small non-coding RNAs as epigenetic regulators. Epigenom Nutr.2019: 14

[46] Tirado LR, Madera MW, González FD. Interacciones genéticas y epigenéticas relacionadas con fisuras de labio leporino y paladar no sindrómicas. 2016; 32(1): 21-34.

[47] Alegría-Torres JA, Baccarelli A, Bollati V. Epigenetics and lifestyle. Epigenomics. 2011; 3(3): 267-277.

[48] Nishida N, Kudo M. Oxidative Stress and Epigenetic Instability in Human Hepatocarcinogenesis. Digestive Diseases. 2013; 31: 447-453

[49] Triff K, Kim E, Chapkin RS. Chemoprotective epigenetic mechanisms in a colorectal cancer model: Modulation by n-3 PUFA 
in combination with fermentable fiber Curr Pharmacol Rep. 2015; 1(1): $11-20$

[50] Lumey LH, Stein AD, Kahnhs, et al. Cohort Profile: The Dutch Hunger Winter Families Study. Inter J Epidemiol.2007; 36: 1196 1204.

[51] Munetsuna E, Yamazaki M, Ohashi K, Yamada H. Epigenetics and fructose metabolism: A new mechanism of fructose effects. Mol Nutr Carb. 2019.

[52] Meng Q, Ying Z, Noble E, Zhao Y, Agrawal R, Mikhail A, et al Systems Nutrigenomics Reveals Brain Gene Networks Linking Metabolic and Brain Disorders. EBioMedicine. 2016: 153-166.

[53] Sadli N, Ackland L, De Mel D, Sinclair AJ, Suphioglu C. Effects of Zinc and DHA on the Epigenetic Regulation of Human Neuronal Cells. Cell Pshycol Biochem.2012; 29: 87-98.

[54] Karimi M, Vedin I, Freud Levi Y, Basun H, Faxén G, Eriksdotter, et al. DHA-rich $\mathrm{n}-3$ fatty acid supplementation decreases DNA methylation in blood leukocytes: the OmegAD study. Am J Clin Nutr.2017;106: 1157-1165.

[55] Quintanilha BJ, Reis BZ, Duarte et al. G, Cozzolino, \& Rogero, M. Nutrimiromics: Role of microRNAs and Nutrition in Modulating Inflammation and Chronic Diseases. Nutrients, 2017; 9(11):_1-24.

[56] Adaikalakoteswari A, Finer S, Voyias PD, McCarthy CM, Vatish M, Moore J, et al. Vitamin B12 insufficiency induces cholesterol biosynthesis by limiting s-adenosylmethionine and modulating the methylation of SREBF1 and LDLR genes. Clin Epigenetics. 2015; 7(14): $1-14$.

[57] Casanueva E, Drijanski A, Fernández-Graxiola AC, Meza C, Pfeffer F. Folate deficiency is associated with obesity and anemia in mexican urban women. Nutr Reseach.2000; 20(10): 1389-1394.

[58] Mahajan, A., Sapehia, D., Thakur, S. et al. Effect of imbalance in folate and vitamin B12 in maternal/parental diet on global methylation and regulatory miRNAs. Sci Rep. 2019; 9, 17602-17623.

[59] Agodi A, Barchitta M, Quattrocchi A, Maugeri A, Canto C, Marchese $\mathrm{AE}$, et al. Low fruit consumption and folate deficiency are associated with LINE-1 hypomethylation in women of a cancer-free population. Gene Nutr. 2015; 10(30): 1-10.

[60] Li S, Yang Q, Hou Y. Hypomethylation of LINE-1 elements in schizophrenia and bipolar disorder. J Psychol Research. 2018; 107 : 68-72.

[61] Altobelli G, Bogdarina IG, Stupka E, Clarck JL, Langley- Evans S. Genome-Wide Methylation and Gene Expression Changes in Newborn Rats following Maternal Protein Restriction and Reversal by Folic Acid. Plos One. 2013; 8(12): 1-11.

[62] Kotsopoulos J, Sohn KJ, Kim JI. Postweaning Dietary Folate Deficiency Provided through Childhood to Puberty Permanently Increases Genomic DNA Methylation in Adult Rat Liver. J Nut. 2008 : 702-709.
[63] Galligan JJ, Rose KL, Beavers WN, Hill S, Tallman KA, Tansey WP et al. Stable Histone Adduction by 4-Oxo-2-nonenal: A Potential Link between Oxidative Stress and Epigenetics. J Am Chem Soc.2014; 136: $11864-11866$.

[64] Guillaumet-Adkins A, Yañez Y, Peris-Diaz MD, Calabria I, PalancaBallester C, Sandoval J. Epigenetics and Oxidative Stress in Aging. Oxid Med Cell Longev. 2017: 1-9.

[65] Wyck S, Herrera C, Requena CE, Bittner L, Hajkova P, Bollwein, et al. Oxidative stress in sperm affects the epigenetic reprogramming in early embryonic development. Epigenetics Chromatin. 2018; 11(60): $1-17$.

[66] Wongpaiboonwattana W, Tosukhowong T, Dissayabutra T, Mutirangura D, Boonla C. Oxidative Stress Induces Hypomethylation of LINE-1 and Hypermethylation of the RUNX3 Promoter in a Bladder Cancer. Asian Pacific Journal of Cancer Prevention. 2013; 14: 372-378.

[67] Cordero-Sánchez P, Milagro- Yoldi FI, Campión-Zabalza J \& Martínez- Hernández JA. Epigenética nutricional: Una pieza clave en el rompecabezas de la obesidad. Rev Esp Ob. 2010; 8(1): 10-21.

[68] Padhye S, Ahmad A, Oswal N, Sarkar FH. Emerging role of Garcinol, the antioxidant chalcone from Garcinia indica Choisy and its synthetic analogs. J Hematol Oncol.2009; 2(38): 1-13.

[69] González de Mejía E. El efecto quimioprotector de té y sus compuestos. Arch Lat Nut. 2003; 53(2): 111-118.

[70] Veléz-Marín M, Uribe-Velázquez LF, Lenz-Souza MI, Papel del resveratrol de uva como antioxidante. Rev Luna Azul.2012; 32: 1-17.

[71] Hernando-Requejo O, García de Quinto H, Rubio Rodríguez MC, Nutrición como factor epigenético regulador del cáncer. Nut Hosp.SF 36(3): 1-15.

[72] García Triana BE, Saldaña Bernabeu A, Saldaña García, El estrés oxidativo y los antioxidantes en la prevención del cáncer. Rev Haban CC méd. 2013; 12(2): 187-96.

[73] Rozano Ladrón de Guevara V, Quiroz Santiago C, Acosta Pulido JC, et al., Pimentel Ayaquica LA., Quiñones Ramírez EI. Hortalizas, las llaves de la energía. Rev Digital Univ. 2004; 5(7): 1-30.

[74] Marquetti Hernández A, Gessner R, Las cadherinas en el diagnóstico histopatológico y pronóstico del carcinoma de células renales. Rev haban cienc méd.2011;10(1): 45-53

[75] Soto-Bernardini MC, Raventós-Vorst H, Papel del estrés oxidativo en la esquizofrenia. Acta Méd Costarric. 2008; 50(4): 197-203.

[76] Gra Menéndez S, Padrón Pérez N, Llibre Rodríguez J, Péptido beta amiloide, proteína Tau y enfermedad de Alzheimer. Rev Cubana Invest

[77] Meldrum DR, Morris MA, Gambone JC. Obesity pandemic: causes, consequences, and solutions - but do we have the will? Fertility and Sterility.2017; 107(4): 833-839 